\title{
IL-6 deficiency in mice neither impairs induction of metabolic genes in the liver nor affects blood glucose levels during fasting and moderately intense exercise
}

\author{
L. Fritsche • M. Hoene • R. Lehmann • H. Ellingsgaard • \\ A. M. Hennige • A. K. Pohl • H. U. Häring • \\ E. D. Schleicher • C. Weigert
}

Received: 21 December 2009 /Accepted: 2 March 2010/Published online: 22 April 2010

(C) Springer-Verlag 2010

\begin{abstract}
Aims/hypothesis Fasting and exercise are strong physiological stimuli for hepatic glucose production. IL-6 has been implicated in the regulation of gluconeogenic genes, but the results are contradictory and the relevance of IL- 6 for fasting- and exercise-induced hepatic glucose production is not clear.

Methods Investigations were performed in rat hepatoma cells, and on C57B16 and $\mathrm{Il}^{/-}$mice under the following conditions: IL-6 stimulation/injection, non-exhaustive exercise (60 min run on a treadmill) and fasting for $16 \mathrm{~h}$. Metabolite analysis, quantitative real-time PCR and immunoblotting were performed.

Results IL-6 stimulation of rat hepatoma cells led to higher glucose production. Injection of IL-6 in mice slightly increased hepatic Pepck (also known as Pck1) expression. Fasting of $1 l \sigma^{-1}$ mice for $16 \mathrm{~h}$ did not alter glucose production compared with wild-type mice, since plasma glucose concentrations were similar and upregulation of
\end{abstract}

L. Fritsche and M. Hoene contributed equally to this study.

Electronic supplementary material The online version of this article (doi:10.1007/s00125-010-1754-4) contains supplementary material, which is available to authorised users.

L. Fritsche $\cdot$ M. Hoene $\cdot$ R. Lehmann $\cdot$ A. M. Hennige $\cdot$

A. K. Pohl $\cdot$ H. U. Häring $\cdot$ E. D. Schleicher $\cdot$ C. Weigert $(\triangle)$

Department of Internal Medicine,

Division of Pathobiochemistry and Clinical Chemistry,

University of Tuebingen,

Otfried-Mueller-Straße 10,

72076 Tuebingen, Germany

e-mail: Cora.Weigert@med.uni-tuebingen.de

H. Ellingsgaard

Division of Endocrinology and Diabetes and Center for Integrated

Human Physiology, University Hospital of Zurich,

Zurich, Switzerland phosphoenolpyruvate carboxykinase (PEPCK) and $P g c-1 \alpha$ (also known as Ppargcla) expression was comparable. In the non-fasting state, $I l \sigma^{-1}$ mice showed a mild metabolic alteration including higher plasma glucose and insulin levels, lower NEFA concentrations and slightly increased hepatic PEPCK content. Moderately intense exercise resulted in elevated IL-6 plasma levels in wild-type mice. Despite that, plasma glucose, insulin, NEFA levels and hepatic glycogen content were not different in $\mathrm{Il \sigma}^{/-}$mice immediately after running, while expression of hepatic $G 6 p c, P g c-1 \alpha$, Irs 2 and $I g f b p 1$ mRNA was similarly increased.

Conclusions/interpretation These data suggest that in mice IL-6 is not essential for physiologically increased glucose production during fasting or non-exhaustive exercise.

Keywords Animal · Carbohydrate metabolism · Exercise . Mouse

\section{Abbreviations \\ 8-CPT-cAMP 8-(4-Chlorophenylthio)adenosine 3',5'-cyclic monophosphate sodium salt \\ G6Pase Glucose 6-phosphatase \\ PEPCK Phosphoenolpyruvate carboxykinase \\ STAT3 Signal transducer and activator of transcription}

\section{Introduction}

Hepatic glucose production is essential for the maintenance of glucose homeostasis and for glucose supply to other tissues. Glycogen breakdown contributes substantially to hepatic glucose delivery, but glycogen stores are limited 
and de novo synthesis of glucose from gluconeogenic precursors is necessary for systemic fuel availability during an overnight fast or under conditions of high energy demand such as prolonged physical activity [1-3]. Gluconeogenesis is mainly controlled by the activity of the key enzymes glucose 6-phosphatase (G6Pase) and phosphoenolpyruvate carboxykinase (PEPCK). Expression of the genes encoding the above is under tight control of insulin and glucagon. IL- 6 has also been implicated in the regulation of these genes. Studies using cultured rat hepatocytes showed that incubation with IL-6 attenuated glucagon-induced Pepck (also known as Pckl) expression [4] or inhibited dexamethasone/cAMP-induced Pepck and G6pase (also known as G6pc) expression [5]. Intraperitoneal application of IL-6 inhibited the increase in Pepck mRNA during the initial phase of fasting in rats [6]. Mice secreting IL-6 from injected tumours had decreased G6Pase activity and mRNA levels in the liver, while the activity of PEPCK was not affected [7]. The most important downstream signal transducer of IL-6 is signal transducer and activator of transcription 3 (STAT3), the tyrosine phosphorylation of which induces dimerisation and activation of IL6 [8]. Mice with a liver-specific STAT3 deficiency had increased levels of gluconeogenic enzymes, while liverspecific production of a constitutively active form of STAT3 repressed their transcription [5]. Further studies revealed that STAT3 targeted the regulatory promoter regions of gluconeogenic genes in vivo [9]. While these data clearly point to an inhibitory effect of IL- 6 on hepatic glucose production, other studies have shown stimulation of gluconeogenesis by IL-6 in rat hepatocytes [10] and transcriptional upregulation of the G6pase promoter by IL6-mediated activation of STAT3 [11]. Furthermore, IL-6 could increase hepatic glucose release, since it stimulated glycogenolysis in rat hepatocytes [12, 13]; more importantly, subcutaneous IL-6 administration in humans resulted in higher plasma glucose levels [14]. From these contradictory results, we hypothesised that IL-6 has the ability to regulate hepatic glucose production, but that the specific outcome depends on superior regulatory mechanisms such as the action of insulin and glucagon, and the presence of further regulatory hormones and cytokines.

Two relevant physiological situations with a special need for hepatic glucose output are fasting and prolonged exercise. It has been suggested that exercise-induced IL-6 production and release from the working muscle, leading to elevated IL-6 plasma levels $[15,16]$, might enhance hepatic glucose production during exercise [17]. $I l \sigma^{-1}$ mice had lower endurance capacity shown as time till exhaustion on a treadmill, possibly explained by impaired hepatic glucose production [18]. However, a direct effect of exerciseinduced IL-6 production on hepatic metabolism has yet to be demonstrated. Moreover it is unclear whether IL-6- dependent signal transduction in the liver is important during fasting.

Here we used $\mathrm{Il}^{-/}$mice to study the regulation of hepatic glucose production, expression of gluconeogenic regulators and hepatic IL-6 signalling during fasting and moderately intense exercise in the absence of IL-6. We also studied the direct effect of IL- 6 on glucose production from lactate in rat hepatoma cells, as well as the direct effect of IL-6 on expression of Pepck and G6pase in the liver of wild-type mice. Our data revealed that IL-6 is able to stimulate glucose production from lactate in vitro and to increase hepatic Pepck expression in mice, but is dispensable for fasting- or moderate exercise-induced glucose production in $\mathrm{Il}^{-1}$ mice.

\section{Methods}

Materials Fao rat hepatoma cells were from the European Collection of Cell Cultures (http://www.hpacultures.org.uk/ products/celllines/index.jsp). Recombinant mouse and rat IL-6 was from R\&D Systems (Wiesbaden-Nordenstadt, Germany). DL-lactate, dexamethasone and 8-(4-chlorophenylthio)adenosine 3 ',5'-cyclic monophosphate sodium salt (8-CPT-cAMP) were from Sigma (Munich, Germany). Cell culture media and supplements were from Lonza (Basel, Switzerland). Cell proliferation reagent WST-1 was from Roche (Mannheim, Germany). The antibody against PEPCK was from Santa Cruz Biotechnology (Santa Cruz, CA, USA). Antibodies against phospho-STAT3 Tyr 705, STAT3 and $\beta$-actin were from Cell Signaling Technology (Frankfurt, Germany). The IRS-2 protein antibody was from Millipore (Schwalbach, Germany).

Cell culture Fao cells were kept in RPMI 1640 medium supplemented with $10 \%$ (vol./vol.) FCS, $100 \mathrm{U} / \mathrm{ml}$ penicillin and $100 \mu \mathrm{g} / \mathrm{ml}$ streptomycin. For experiments the cells were starved overnight in a serum- and glucose-free medium containing $2 \mathrm{mmol} / \mathrm{l} \mathrm{DL}-$ lactate. On the following day cells were treated with $20 \mathrm{ng} / \mathrm{ml} \mathrm{IL}-6,0.1 \mu \mathrm{mol} / 1$ dexamethasone and $0.1 \mathrm{mmol} / 1 \mathrm{8}$-CPT-cAMP in glucose- and serum-free medium containing $10 \mathrm{mmol} / 1 \mathrm{dL}$-lactate for 5 and $24 \mathrm{~h}$ respectively.

Animal care All animal experiments were conducted in accordance with the guidelines for laboratory animal care and were approved by the local governmental commission for animal research (Regierungspraesidium). Male C57B1/6J mice and $\mathrm{Il}^{--}\left(\mathrm{B} 6.129 \mathrm{~S} 2-\mathrm{Il}^{\mathrm{tmlKopf}} / \mathrm{J}\right)$ mice maintained on a C57Bl/6J-background were purchased from Jackson Laboratory (Bar Harbor, ME, USA) and kept under an inverted light-dark cycle (dark period 09:30-21:30 hours, light period 21:30-09:30 hours) with free access to standard chow (Sniff, Soest, Germany) and tap water. 
For acute IL-6 application, a bolus of IL-6 $(2 \mu \mathrm{g} / \mathrm{kg})$ was injected intraperitoneally in non-fasted 12-week-old male C57Bl/6 mice. For fasting experiments, 11- to 14-week-old mice were either fasted over $16 \mathrm{~h}$ or had free access to standard lab animal chow.

Exercise experiments were performed between 10:00 and 14:00 hours. Mice (12-week-old) habituated to treadmill running on a treadmill with motorised grade adjustment (Mouse Accupacer; Hugo Sachs Elektronik, March-Hugstetten, Germany) ran for $60 \mathrm{~min}$ at $14 \mathrm{~m} / \mathrm{min}$ and $14^{\circ}$ inclination after $5 \mathrm{~min}$ warm-up $\left(5 \mathrm{~m} / \mathrm{min}\right.$ at $5^{\circ}$ inclination). Mice attempting to rest were encouraged to continue running by gently tapping on their back. Mice in the sedentary group had no access to food for the last $60 \mathrm{~min}$ before being killed. Exercised animals were killed immediately after running. All animals were anaesthetised with an intraperitoneal injection of ketamine $(150 \mathrm{mg} / \mathrm{kg}$ body weight) and xylazine (10 $\mathrm{mg} / \mathrm{kg}$ body weight) and killed by decapitation. Liver tissues were immediately removed and frozen in liquid nitrogen or directly processed for protein analysis.

Blood variables Non-esterified fatty acids, triacylglycerol and hormones were measured in the EDTA-plasma collected after decapitation. NEFA and triacylglycerol concentrations were detected by a fully automatic enzymatic method on a multi analyser (ADVIA 1650; Siemens Health Care Sector, Fernwald, Germany). Insulin and glucagon levels were measured by radio-immunoassay (Linco Research, St Charles, MO, USA), and IL-6 and leptin by a kit (mouse Luminex; Linco Research). Glucose was quantified in capillary blood samples taken from the tail vein using a glucometer (Accu-Chek Aviva; Roche, Mannheim, Germany). For the glucose tolerance test, mice were fasted for $16 \mathrm{~h}$ prior to i.p. injection of glucose ( $2 \mathrm{mg} / \mathrm{g}$ body weight). For the insulin tolerance test, mice had free access to chow prior to i.p. injection of $0.5 \mathrm{mU}$ insulin $/ \mathrm{g}$ body weight (Insuman rapid; sanofi-aventis, Frankfurt am Main, Germany). Blood glucose levels were determined at the indicated time points following respective injections.

Cell/ tissue lysis and western blotting Cells were lysed in $175 \mu \mathrm{l}$ per well of lysis buffer (50 mmol/1 HEPES, pH 7.5; $150 \mathrm{mmol} / 1 \mathrm{NaCl} ; 1.5 \mathrm{mmol} / 1 \mathrm{MgCl}_{2} ; 1 \mathrm{mmol} / 1$ EDTA; $10 \%$ (vol./vol.) glycerin; 1\% (vol./vol.) Triton X-100) containing protease and phosphatase inhibitors. Protein $(250 \mu \mathrm{g})$ of total extracts was separated by SDS-PAGE (7.5\%, vol./vol.) and western blot analysis was performed as described elsewhere [19].

Liver tissue aliquots were immediately homogenised at $4{ }^{\circ} \mathrm{C}$ in lysis buffer $(50 \mathrm{mmol} / 1 \mathrm{TRIS}, 150 \mathrm{mmol} / \mathrm{l} \mathrm{NaCl}, 1 \%$ [vol./vol.] Triton X-100) containing protease inhibitor (Complete; Roche) and phosphatase inhibitors. Homoge- nates were allowed to solubilise for $30 \mathrm{~min}$ on ice and were then clarified by three subsequent centrifugation steps at $13,000 \times \mathrm{g}$ for $15 \mathrm{~min}$. For detection of protein levels and phosphorylation, $150 \mu \mathrm{g}$ of total protein were used.

Gene expression Frozen liver tissue was homogenised in a device (TissueLyser; Qiagen, Hilden, Germany) and total RNA was extracted using a kit (RNeasy mini; Qiagen) according to the manufacturer's instructions. Total RNA from Fao cells was also extracted using the same kit. For reverse transcription PCR, $1 \mu \mathrm{g}$ of RNA was used with random hexamer primers and a cDNA synthesis kit (Transcriptor First Strand; Roche) according to the manufacturer's instructions. RNA expression was measured by real-time quantitative PCR on the Light Cycler 480 System (Roche) using kits (FastStart DNA-MasterSYBR Green I; Roche; or QuantiFast SYBR Green PCR Kit; Qiagen). The primer sets used and cycling conditions are described in the Electronic supplementary material (ESM) Table 1. The mRNA content is given in arbitrary units. Normalisation to $\beta$-actin mRNA content generated results comparable to non-normalised values.

Glycogen content Glycogen levels were determined by a modification of the procedure described by Chan and Exton [20]. Liver tissue was weighted and solubilised for $10 \mathrm{~min}$ with $250 \mu 130 \% \mathrm{KOH}$ at $90^{\circ} \mathrm{C}$. Glycogen was precipitated by centrifugation $\left(30 \mathrm{~min}\right.$ at $10,000 \times \mathrm{g}$ and $4^{\circ} \mathrm{C}$ ) after adding 0.2 volumes $1 \mathrm{~mol} / 1 \mathrm{Na}_{2} \mathrm{SO}_{4}$ and three volumes $100 \%$ ice-cold ethanol. The precipitate was washed twice with $70 \%$ ethanol, dried and then hydrolysed for $1 \mathrm{~h}$ with $250 \mu 11 \mathrm{~mol} / 1 \mathrm{HCl}$ at $90^{\circ} \mathrm{C}$. After neutralisation with $1 \mathrm{~mol} / \mathrm{l} \mathrm{NaOH}$, glucose was determined enzymatically (ADVIA 1650; Siemens Health Care).

Statistical analysis Means \pm SEM were calculated and groups of data were compared using Student's $t$ test and a statistical software package (JMP 4.0; SAS Institute, Cary, NC, USA). Statistical significance was set at $p<0.05$.

\section{Results}

Effect of IL-6 on glucose production of Fao hepatoma cells First we studied the effect of IL-6 on glucose production and expression of gluconeogenic enzyme genes Pepck and G6pase in rat hepatoma cells. This cell line is able to produce glucose from gluconeogenic precursors and release glucose into the supernatant fraction. Providing lactate to the cells induced production of considerable amounts of glucose after $5 \mathrm{~h}$ (Fig. 1a) and $24 \mathrm{~h}$ (Fig. 1b), this process being enhanced by dexamethasone, a wellknown stimulator of gluconeogenesis (Fig. 1a, b), and 
Fig. 1 Effect of IL-6 on glucose production of Fao hepatoma cells. Fao cells were cultured in RPMI in the presence or absence of $10 \mathrm{mmol} / \mathrm{l}$ lactate, $20 \mathrm{ng} / \mathrm{ml} \mathrm{IL-6,} 0.1 \mu \mathrm{mol} / \mathrm{l}$ dexamethasone and $0.1 \mathrm{mmol} / \mathrm{l}$ 8-CPT-cAMP. Glucose concentration was measured in the supernatant fraction after $5 \mathrm{~h} \mathrm{(a)}$ or $24 \mathrm{~h}(\mathbf{b})$. Glucose produced from lactate was set to $100 \%$. Values are mean \pm SEM, $n=4$, ${ }^{*} p<0.05$ vs $10 \mathrm{mmol} / 1$ lactate. c, d Cells were lysed for preparation of RNA and mRNA content of Pepck, G6pase (e, f) and Socs 3 (h) was measured. $\mathbf{g}$ Duplicates of protein lysates were separated by $7.5 \%$ SDS-PAGE and immunoblotted with anti-phospho-STAT3 and STAT3 protein antibodies. mRNA values $(\mathbf{c}-\mathbf{f}, \mathbf{h})$ are shown as arbitrary units, $n=7$, mean \pm SEM, $* p<0.05$ vs $10 \mathrm{mmol} / 1$ lactate

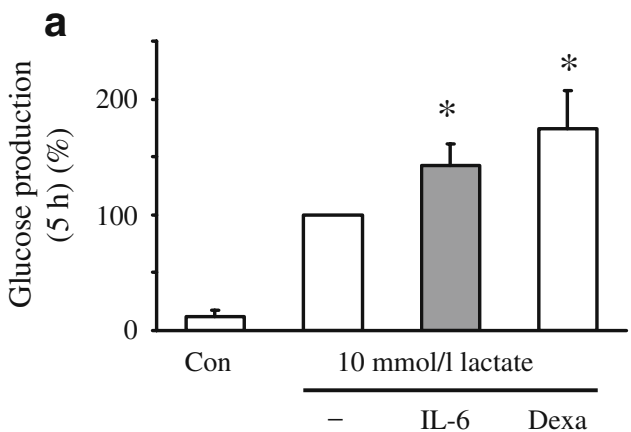

b
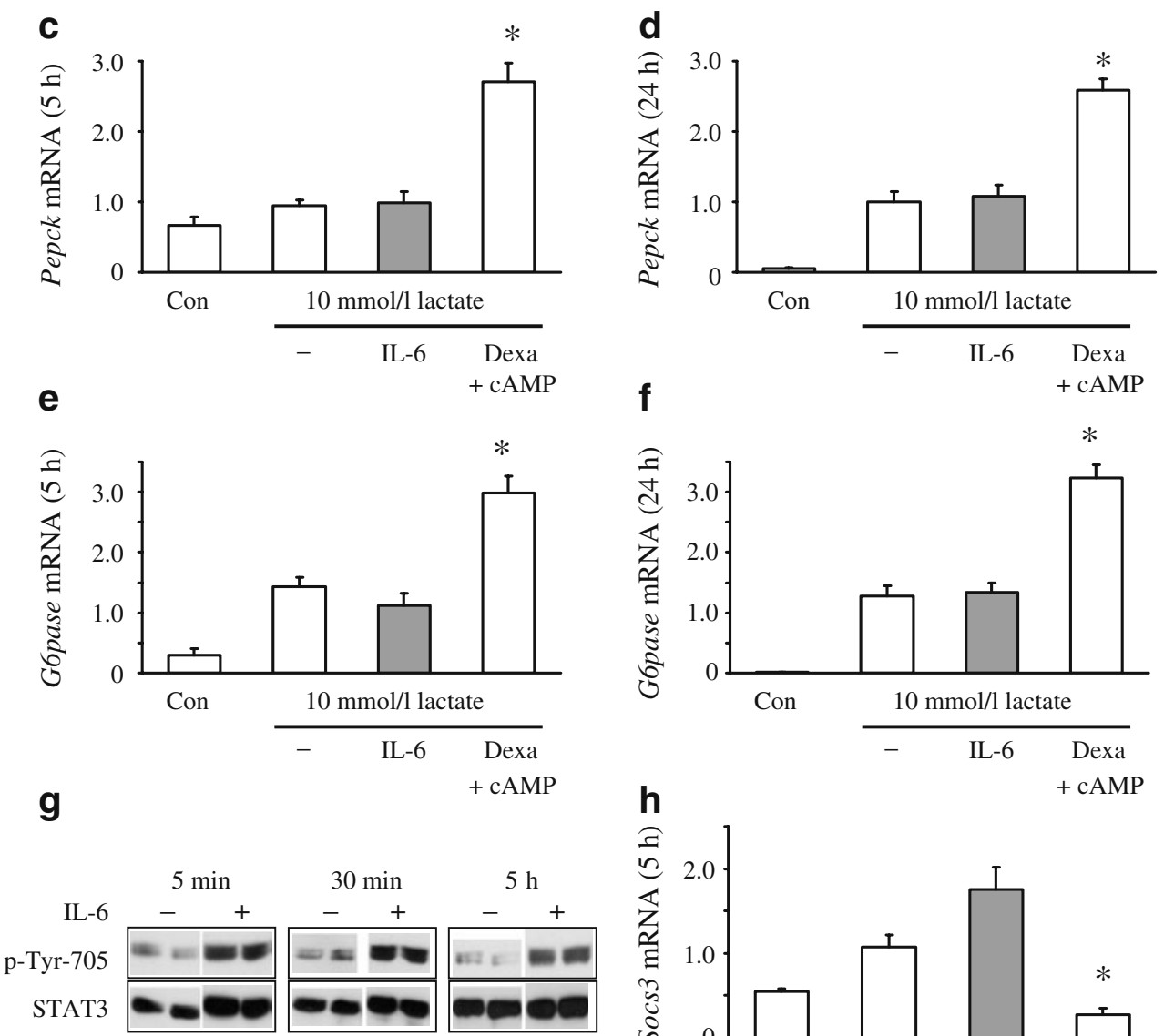
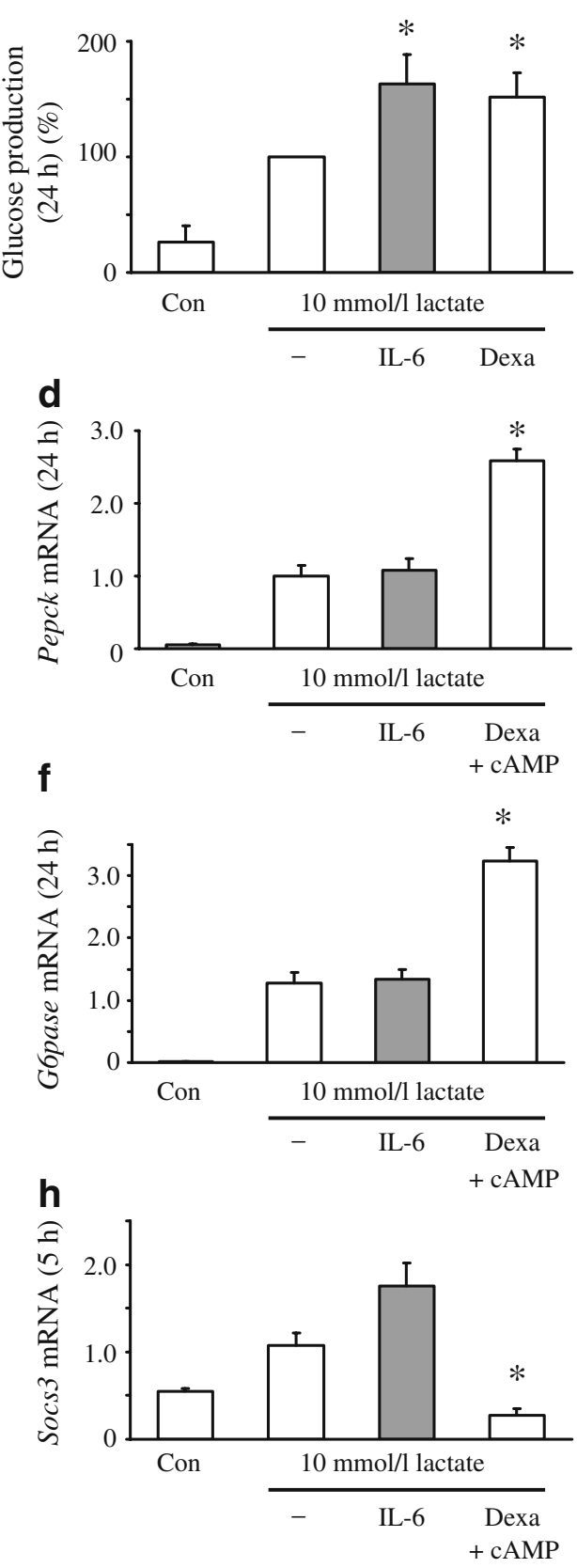

reduced by insulin (data not shown). The presence of IL-6 resulted in a significantly higher rate of glucose production than with lactate alone after $5 \mathrm{~h}$ and $24 \mathrm{~h}$ (Fig. 1a, b). We were unable to detect a considerable effect of IL-6 on glucose release in the absence of lactate, arguing against stimulation of glycogenolysis as a source of glucose in our experiments (data not shown). Despite that effect on glucose production, the expression of Pepck and G6pase mRNA was not influenced by treatment with IL-6. Expression levels of both enzymes were strongly increased after $24 \mathrm{~h}$ by addition of lactate, and to a lesser extent after $5 \mathrm{~h}$, without any further effect of IL-6 (Fig. 1c-f), while the combination of dexamethasone and cAMP (given as cellpermeable 8-CPT-cAMP) had a strong additive effect. However, under these conditions IL-6 stimulation increased phosphorylation of STAT3 (Fig. 1g) and expression of Socs3 (Fig. 1h; $p=0.08$ IL-6 vs lactate alone), which demonstrated activation of IL-6-dependent gene expression. We also observed a significant decrease of Socs 3 expression by dexamethasone/cAMP (Fig. 1h), but this was not further evaluated in this study. The viability of the cells was not affected in the presence of IL- 6 as determined by WSTassay $(103 \pm 18 \%$ vs $100 \%$ viability of cells cultured in $10 \mathrm{mmol} / 1$ lactate; data not shown). 
a

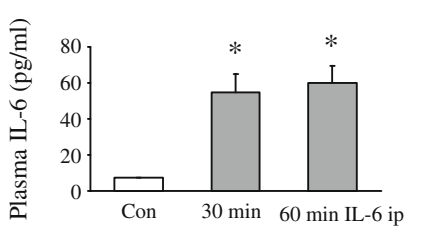

b

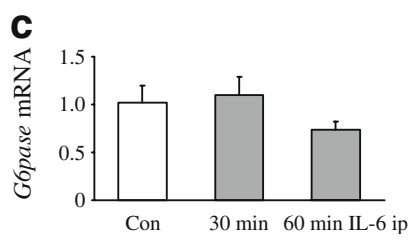

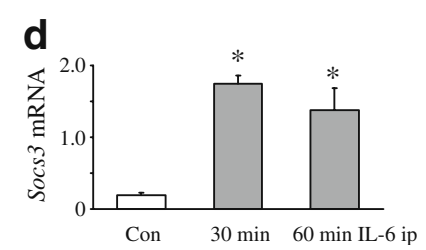

Fig. 2 Effect of acute IL-6 application on hepatic expression of Pepck and G6pase in mice. IL-6 plasma levels (a), and Pepck (b), G6pase (c) and $\operatorname{Socs} 3$ (d) mRNA content of hepatic tissue at 30 or $60 \mathrm{~min}$ after intraperitoneal (ip) IL-6 application $(2 \mu \mathrm{g} / \mathrm{kg})$ or no application (control mice [Con]). Values are mean \pm SEM, $n=6, * p<0.05$ vs Con, ${ }^{\dagger} p<0.06,{ }^{\star} p<0.10$

Effect of acute IL-6 application on hepatic expression of Pepck and G6pase in mice To exclude the possibility that we had missed an effect of IL-6 on expression of gluconeogenic enzyme genes due to limitations of the Fao cell culture model, we injected mice with IL-6 $(2 \mu \mathrm{g} / \mathrm{kg})$ intraperitoneally and studied hepatic gene expression after 30 and $60 \mathrm{~min}$ of treatment. IL-6 plasma levels were strongly increased after 30 and 60 min of injection, but still in a range achieved by intense exercise $(55 \pm 10$ and $60 \pm$ $9 \mathrm{pg} / \mathrm{ml}$, respectively; Fig. 2a). Pepck expression was slightly elevated by IL-6 after both time points, while no increase was detected for G6pase (Fig. 2b, c). Pronounced upregulation of the IL- 6 target gene Socs 3 was found

(Fig. 2d), indicating that the treatment with IL-6 induced a strong effect on genes with IL-6-dependent regulation.

IL-6 deficiency of mice does not impair fasting-induced glucose production, but results in higher glucose levels in the fed state The data obtained in Fao cells and IL-6-treated mice indicated that IL- 6 could be involved in the induction of gluconeogenesis. To test the relevance of IL-6 in vivo, we compared wild-type and $I l 6^{-}$mice in two physiological situations when hepatic glucose production is needed to provide fuels for other organs, namely during fasting and endurance exercise. First we studied the response to a $16 \mathrm{~h}$ fast. As shown in Fig. 3a-d, both genotypes responded to fasting with a decrease in plasma glucose, plasma insulin and plasma triacylglycerol concentrations, and an increase in plasma NEFA levels without any detectable betweengroup difference. The only observed significant difference between both genotypes was that plasma glucose levels in the fed state were higher in $\mathrm{Il}^{-1}$ mice (Fig. 3a).

The fasting-induced upregulation of hepatic PEPCK (Fig. 4a) and IRS-2 protein content (Fig. 4b), and of Pgc$1 \alpha$ (also known as Ppargcla) mRNA expression in the liver (Fig. 4c) was similar in wild-type and $\mathrm{Il}^{-/}$mice. mRNA expression of Pepck, G6pase and Irs2 was not increased comparing the fed with the fasted state, while the immunoblots for G6Pase were inconclusive due to several unspecific bands (data not shown). The only difference between the genotypes was in the fed state, with slightly higher levels of PEPCK in $\mathrm{Il}^{/-}$mice, well in line with the higher plasma glucose levels in these mice when fed. When we studied IL-6-dependent signal transduction under these conditions, we found no indication for its activation by
Fig. 3 IL-6 deficiency in mice does not impair fasting-induced glucose production. Plasma concentrations of glucose (a), insulin (b), NEFA (c) and triacylglycerol (TG) (d) of fed or fasted wild-type (wt) and $I l 6^{-1}$ mice. Values are mean $\pm \mathrm{SEM}$, $n=12, * p<0.05$ vs fed, ${ }^{\dagger} p<0.05 \mathrm{wt}$ vs $I l \sigma^{-}$
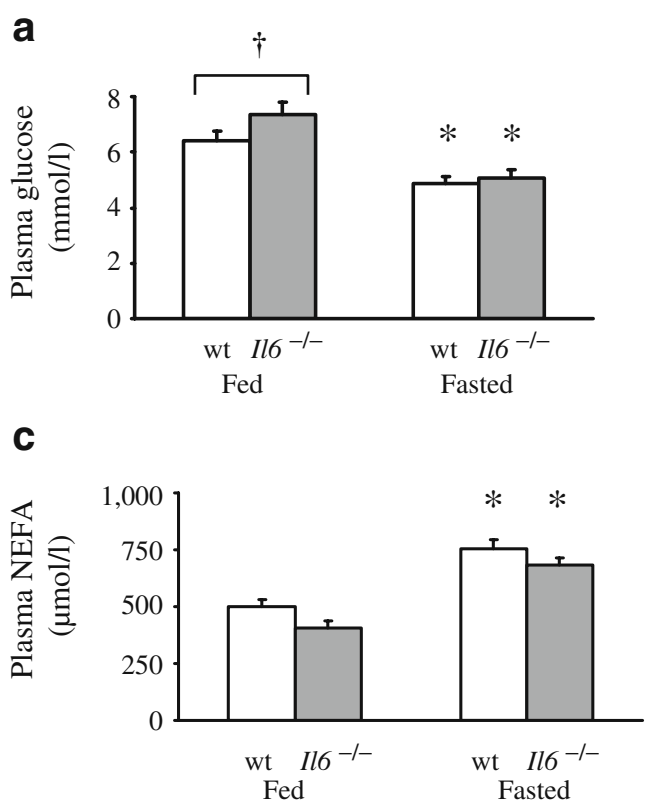

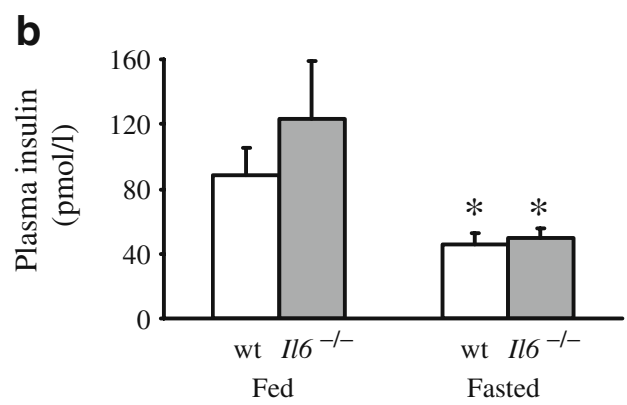

d

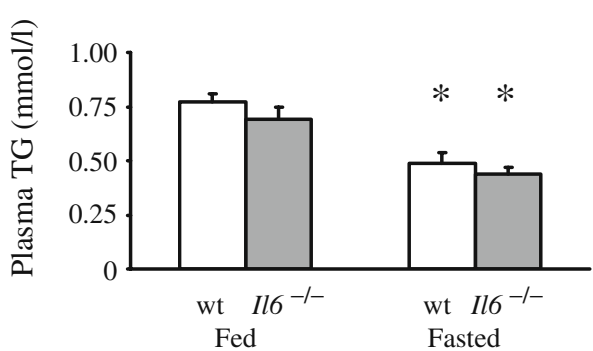


Fig. 4 Fasting-induced gene expression in the liver of wildtype (wt) and $I l \sigma^{-1}$ mice. (a) Blots of PEPCK and (b) IRS-2 protein content in relation to $\beta$-actin, with densitometric quantification by bar graph. $\mathbf{d}$ Blot showing phosphorylation of STAT3 and STAT3 protein content of hepatic tissue of fed or fasted wild-type and $\mathrm{Il}^{/-}$ mice, with densitometric quantification by bar graph. For blots, protein $(150 \mu \mathrm{g})$ of liver lysates was separated by $7.5 \%$ SDS-PAGE and immunoblotted with anti-PEPCK, anti-IRS-2, anti- $\beta$-actin, anti-phospho STAT3 and anti-STAT3 antibodies. Lysates from two individual animals from each group are shown. c $P g c-1 \alpha$ and (e) Socs 3 mRNA content in liver tissue of fed or fasted wild-type and $I l \sigma^{--}$mice, values shown as arbitrary units. Values $(\mathbf{a}, \mathbf{b}$, d) are mean \pm SEM. $n=12$, ${ }^{*} p<0.05$ vs fed, ${ }^{\dagger} p<0.05 \mathrm{wt}$ vs $I l \sigma^{-},{ }^{\ddagger} p=0.1 \mathrm{wt}$ vs $I l \sigma^{-}$
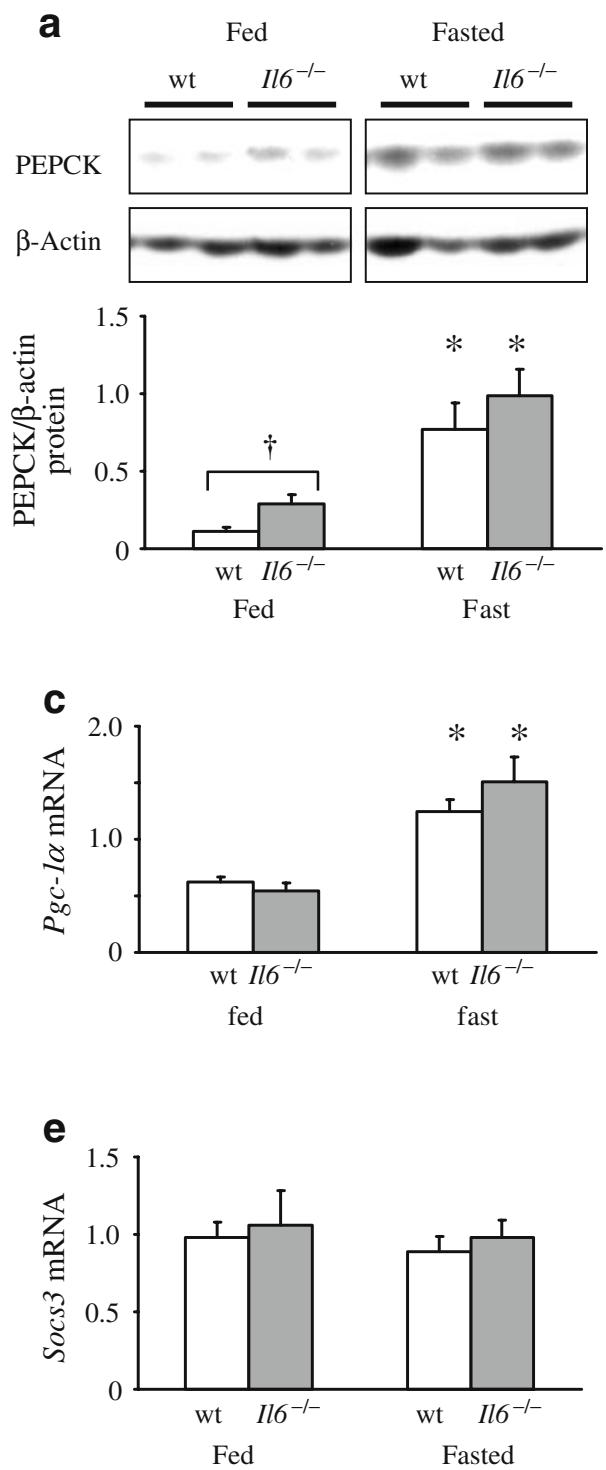
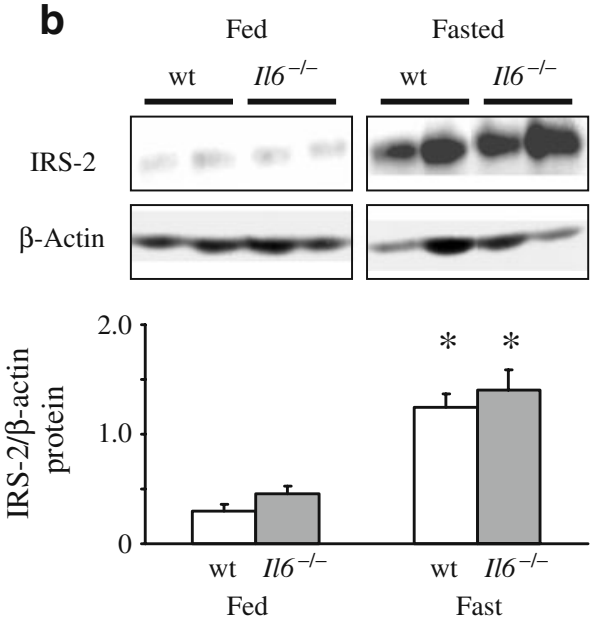

d

Fed

Fasted
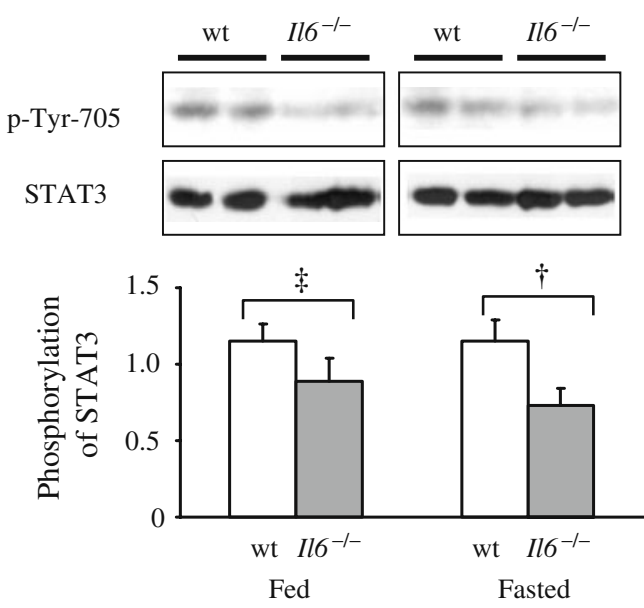

fasting or feeding, either in the form of phosphorylation of STAT3 or changes to Socs3 expression (Fig. 4d, e). Phosphorylation of STAT3 was slightly lower in $\mathrm{IlO}^{-}$ mice (Fig. 4d), but still detectable.

\section{IL-6 deficiency of mice does not impair exercise-induced} glucose production The fact that responses of wild-type and $I l \sigma^{--}$mice in hepatic glucose production and upregulation of gluconeogenic regulators were comparable does not exclude the possibility that lack of IL-6 may become evident in situations when IL-6 plasma levels would be increased and release of IL- 6 into the circulation might fulfil a physiological function, as has been demonstrated during prolonged exercise. Therefore we studied the response of hepatic glucose metabolism to acute exercise after a 60 min treadmill run in wild-type and $\mathrm{Il}^{-/}$mice. No difference was seen in average body weight between the groups $\left(25.6 \pm 1.9 \mathrm{~g}\right.$ in wild-type, $25.1 \pm 2.3 \mathrm{~g}$ in $\mathrm{Il \sigma}^{/-}$ mice). The exercise conditions allowed running at a moderate intensity, with both genotypes able to complete the run without obvious difficulties. The plasma glucose levels before and after the run did not differ between the genotypes, with an average decrease of $2.42 \pm 0.49 \mathrm{mmol} / \mathrm{l}$ in wild-type and $2.41 \pm 0.43 \mathrm{mmol} / 1$ in $\mathrm{IlO}^{-1}$ mice after running (Fig. 5a). NEFA were increased to comparable concentrations after running, while sedentary $\mathrm{Il}^{/-}$mice had lower levels than sedentary wild-type mice ( $486 \pm 63$ vs $606 \pm 59 \mu \mathrm{mol} / \mathrm{l}$; Fig. 5b). Plasma insulin levels were higher in sedentary $\mathrm{Il}^{-1}$ mice, decreasing after exercise in both genotypes to similar values (Fig. 5c). No significant difference in plasma glucagon levels was detected (Fig. 5d), but $I l 6^{--}$mice had a clearly higher insulin/ glucagon ratio in the sedentary state. After exercise, this ratio strongly decreased in both genotypes, resulting in 
Fig. 5 IL-6 deficiency in mice does not impair exerciseinduced hepatic glucose production. Plasma concentrations of glucose (individual values of the same animals before and after exercise bout) (a), and NEFA (b), insulin (c) and glucagons content (d), as well as insulin/glucagon ratio (e) and hepatic glycogen content (f) of sedentary (Sed) and exercised (Run) wild-type (wt) and $I l \sigma^{/-}$ mice. Values are mean \pm SEM, $n=18$ except glucagon $(n=8)$, ${ }^{*} p<0.05,{ }^{*} p=0.06$ vs Pre run/ Sed; ${ }^{\dagger} p<0.05$ wt vs $I l \sigma^{-/}$ a
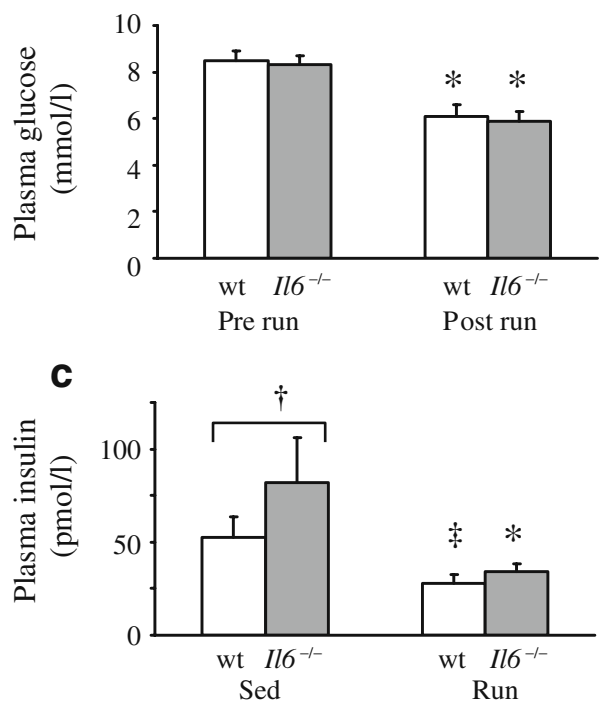

e

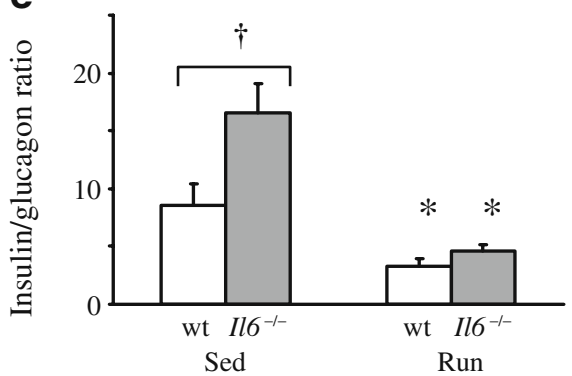

b

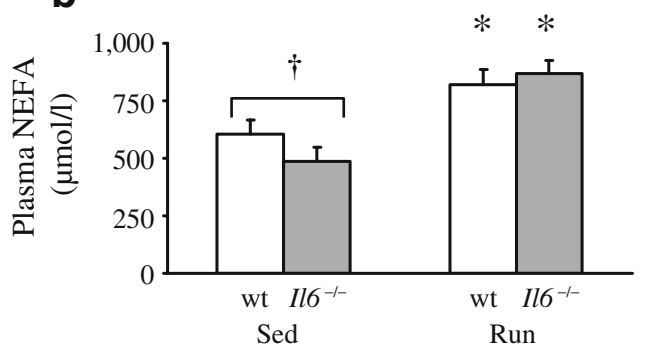

d

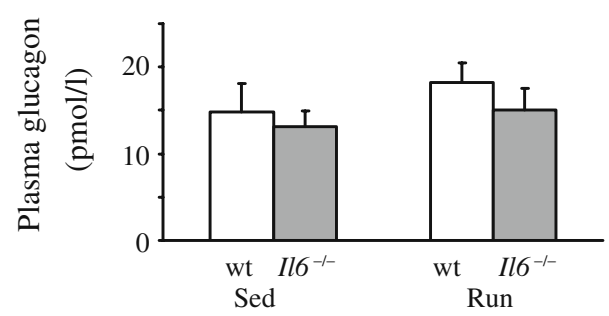

f

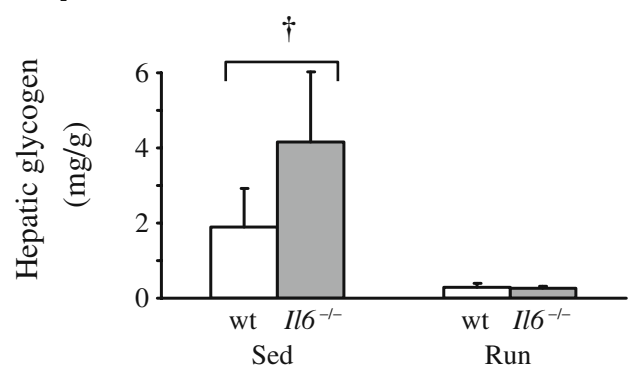

comparable values (Fig. 5e). Hepatic glycogen stores were found to be almost depleted after running, while $\mathrm{Il}^{-1}$ mice had significantly higher glycogen levels in the sedentary state (Fig. 5f).

Determination of mRNA expression of different regulators of glucose metabolism in the liver showed that IL-6 deficiency had no impact on exercise-induced expression of the genes measured, with G6pase (Fig. 6a), Irs2 (Fig. 6d) and Igfbpl (Fig. 6e) significantly upregulated to the same extent, and $P g c-1 \alpha$ expression increased in wild-type and tending to increase in $\mathrm{IlO}^{-1}$ mice (Fig. 6c), while no significant upregulation of Pepck expression was found (Fig. 6b). PEPCK protein levels were also not influenced by the 60 min treadmill run (data not shown). Interestingly, IL-6 plasma levels were increased after running in the wildtype mice, accompanied by increased $I l 6$ and Socs 3 expression in the liver (Fig. 6f-h). However, Socs3 was also induced in the livers of $I l \sigma^{/-}$mice, indicating the existence of additional exercise-related inducers of Socs 3 expression (Fig. 6h). Leptin plasma levels were not increased by exercise in either of the genotypes studied (data not shown). We also studied phosphorylation of STAT3 in the liver of sedentary and exercised wild-type and $\mathrm{IlO}^{/-}$mice, but the inter-individual variance was high and did not allow reliable interpretation of potential differences induced by exercise (data not shown).

Effect of IL-6 deficiency on glucose tolerance The higher insulin and glucose levels in sedentary fed $\mathrm{Il}^{-1}$ mice might have been caused by altered insulin sensitivity in these animals. After an i.p. glucose challenge, neither glucose (Fig. 7a, b) nor insulin levels (data not shown) differed between $I l \sigma^{-/}$and wild-type mice. After an i.p. insulin challenge $I l 6^{/-}$mice had slightly higher glucose levels than wild-type counterparts (Fig. 7c, d).

\section{Discussion}

In this study we investigated the hypothesis that IL- 6 might stimulate hepatic gluconeogenesis and, using IL-6-deficient mice, tested the physiological relevance of IL- 6 for fastingand exercise-induced hepatic glucose production.

IL-6 was found to be a myokine that is produced within the contracting muscle fibres [21] and released into the circulation depending on intensity and duration of exercise $[22,23]$. Further research revealed that IL-6 fulfils some 
Fig. 6 Exercise-induced gene expression in the liver of wildtype and $I l \sigma^{-1}$ mice. G6pase

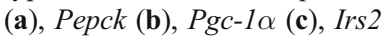

(d), Igfbp1 (e), Il6 (g) and Socs 3

(h) mRNA content in liver tissue of sedentary (Sed) or exercised (Run) wild-type (wt) and $I l \sigma^{--}$mice. Values are shown as arbitrary units, $n=18$. f Plasma concentration of IL-6 in sedentary or exercised wildtype mice, $n=8$. All values are mean \pm SEM. ${ }^{*} p<0.05$, ${ }^{\dagger} p=0.06$ vs sedentary mice a

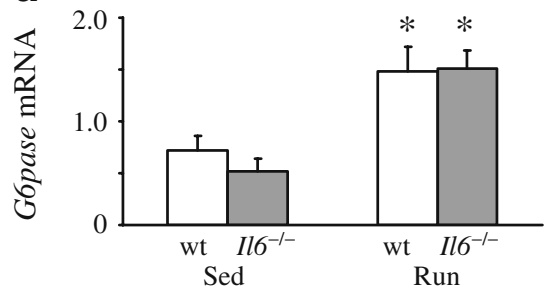

b
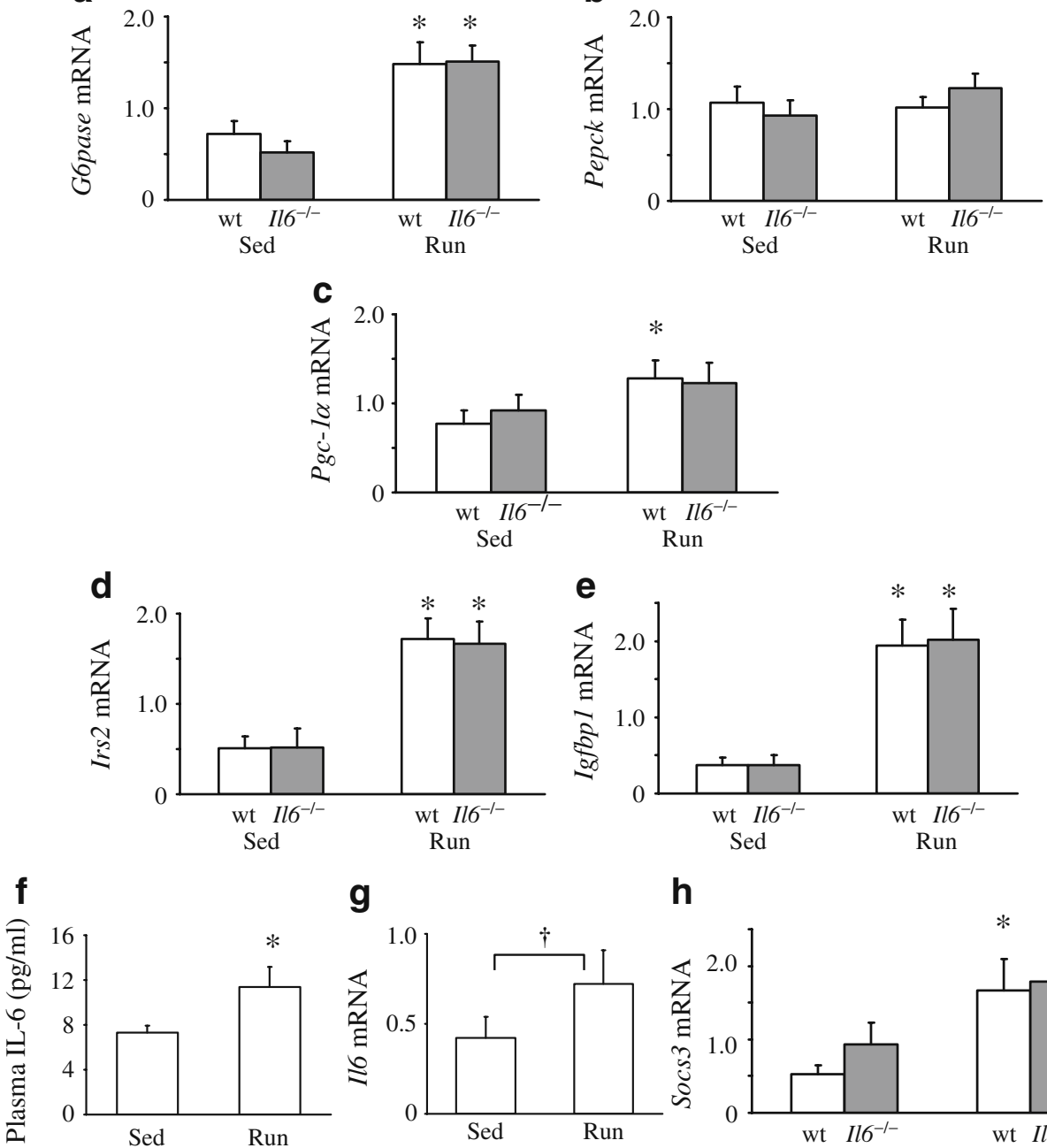

g

h
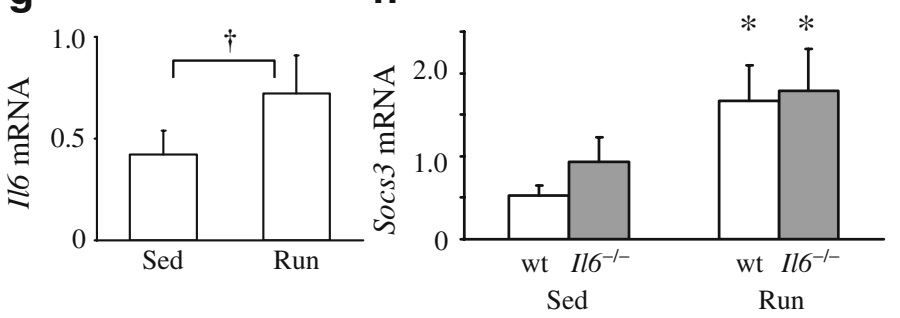

criteria of an exercise factor, because it stimulates glucose uptake $[24,25]$ and fatty acid oxidation in skeletal muscle [26, 27], increases lipolysis [28] and activates AMP-activated protein kinase [29]. Moreover, infusion of IL-6 in humans suggested that IL-6 could enhance endogenous glucose production during prolonged exercise [17] or increase hepatic glucose output [14]. This putative ability of IL-6 to increase hepatic glucose production is further supported by data of the present study, since incubation of rat hepatoma cells with IL6 increased glucose production from lactate and acute application of IL-6 in mice increased hepatic Pepck mRNA expression, with no significant effect on G6pase mRNA content. A similar IL-6-dependent gene regulation of Pepck and G6pase was recently reported for rat livers [30].

In contrast to these direct effects of IL-6 administration, the lack of IL-6 in $I l 6^{-1}$ mice did not seem to reduce hepatic glucose output during moderately intense exercise or fasting, nor was the upregulation of metabolic regulators of glucose metabolism impaired in both conditions. These results suggest that IL-6 is not essential for hepatic glucose production during an overnight fast or a 60 min treadmill run in mice. Interestingly, the exercise conditions used in our study are sufficient to induce IL-6 production. We found $11.4 \pm 4.4 \mathrm{pg} / \mathrm{ml}$ IL-6 in the exercised wild-type mice (compared with $7.3 \pm$ $1.8 \mathrm{pg} / \mathrm{ml}$ in sedentary mice). Since we have also observed enhanced phosphorylation of STAT3 in the working muscles of wild-type, but not of $116^{-/}$mice (C. Weigert, unpublished data), we conclude that skeletal muscle is the source of the IL-6 protein found in the circulation. Interestingly, we detected slightly enhanced Il6 mRNA expression in liver tissue of wild-type mice after exercise, which could be due to a self-stimulatory effect of IL-6 on its own expression [31]. Expression of Socs3, however, was increased to a similar degree after running in wild-type and $I l \sigma^{/-}$mice, suggesting that other stimulatory mechanisms during exercise also lead to enhanced Socs 3 mRNA in the liver.

It is possible that the importance of IL-6 for stimulation of glycogenolysis and gluconeogenesis in mice during physical exercise might only become evident with increasing intensity and duration of exercise. In a recent study 
Fig. 7 Glucose and insulin tolerance test (GTT and ITT). Blood glucose levels were determined at the indicated time points after i.p. injection of glucose $(\mathbf{a}, \mathbf{b})$ or insulin $(\mathbf{c}, \mathbf{d})$. AUC was calculated for plasma glucose (mmol/l glucose $\times$ $60 \mathrm{~min}$ ). Values are means \pm SEM from $n=5$ wild-type (wt) mice (white circles) and $n=5$ $I l \sigma^{/-}$mice (grey circles), ${ }^{*} p<$ 0.05 vs wild-type after $15 \mathrm{~min}$ of insulin i.p., ${ }^{\dagger} p<0.05$ vs wild-type mice
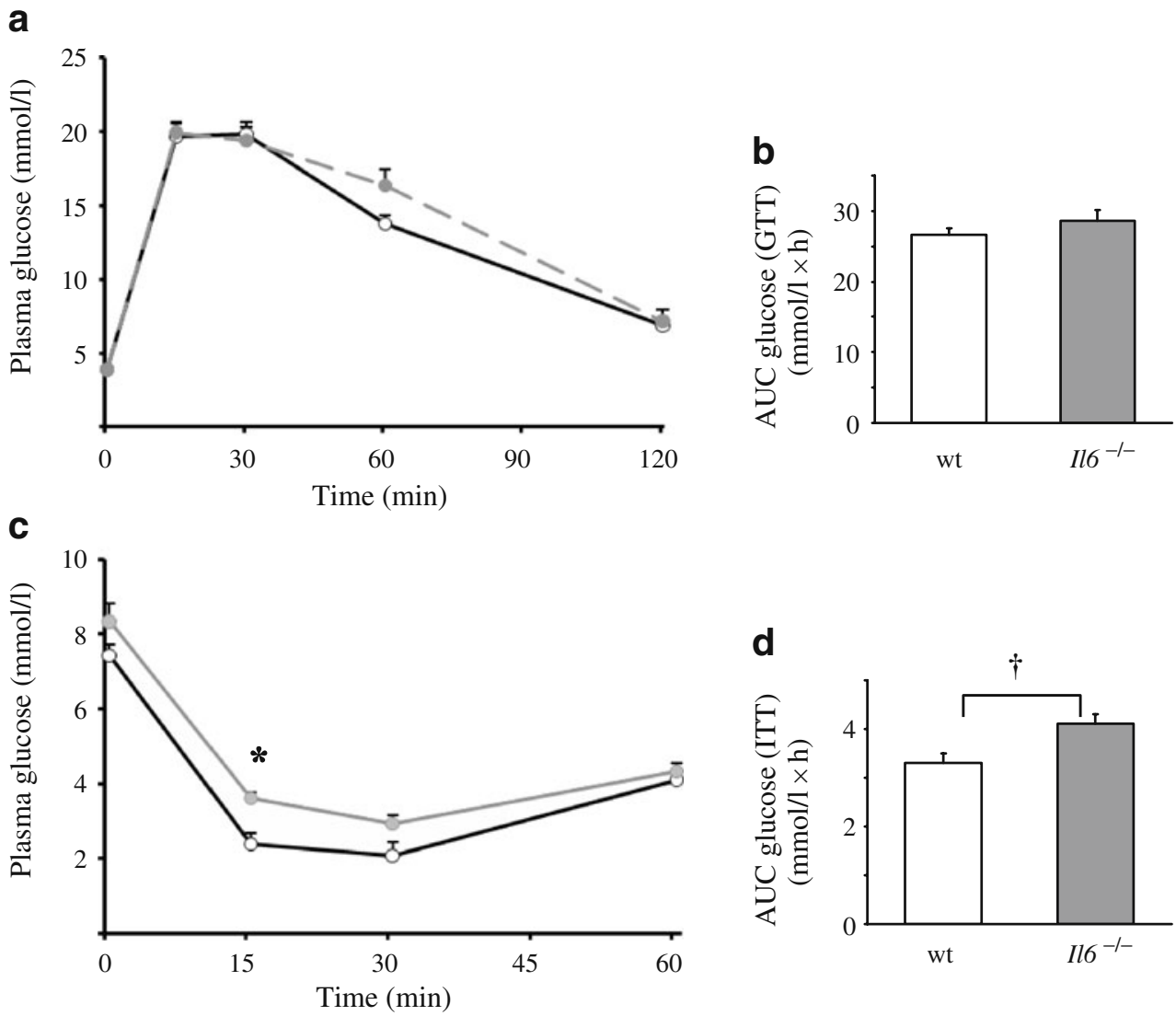

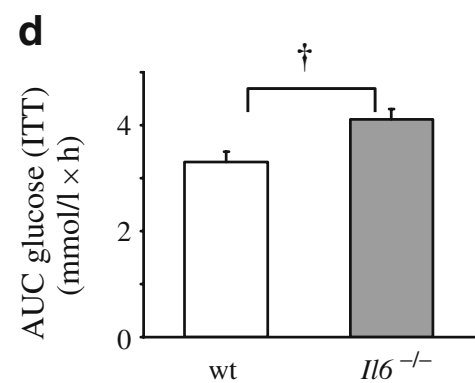

when rats ran till exhaustion (average time on treadmill $123 \mathrm{~min}$ at $22 \mathrm{~m} / \mathrm{min}$ and $5^{\circ}$ inclination), IL- 6 plasma levels were increased above $120 \mathrm{pg} / \mathrm{ml}$ immediately after running, accompanied by a strong increase in hepatic STAT3 phosphorylation and pronounced upregulation of G6pase, Pepck and Pgc-1 $\alpha$ [30]. Our running conditions resulted only in a slight elevation of IL-6 plasma concentrations, with less pronounced upregulation of hepatic $P g c-1 \alpha$ expression, and no increase in hepatic Pepck mRNA content immediately after the run. Therefore if IL-6deficient mice were forced to run till exhaustion, it is possible that lack of IL-6 would result in impaired adaptation of hepatic glucose metabolism to intense and prolonged exercise. However, more rigorous exercise conditions could also lead to hepatic tissue damage and infiltration of inflammatory cells [32], which could stimulate IL-6 production in intrahepatic cells and induce IL-6mediated tissue repair mechanisms [33]. $1 l 6^{/-}$mice have defective liver repair mechanisms and blunted induction of genes involved in cell cycle progression, liver growth and maintenance of metabolic homeostasis, including gluconeogenetic enzyme genes and $I g f b p l$ after partial hepatectomy $[11,34,35]$. It is therefore essential to avoid exhaustive exercise conditions if distinction between metabolic and tissue repair effects of IL-6 is to be made. The mice in our exercise study showed a clear response to a metabolic challenge and the need for hepatic glucose production, since hepatic glycogen was almost completely depleted and the insulin/glucagon ratio dropped significantly. This exercise-induced metabolic stress for the liver was further reflected by the pronounced upregulation of $G 6 p a-$ se, Irs 2 and $I g f b p 1$ expression, genes known to be regulated by the metabolic state of the liver [36, 37]. Moreover, using an exercise protocol with similar intensity and duration, we have recently reported the acute regulation of genes important for glucose and fatty acid metabolism in the liver of wild-type mice [38]. Thus we conclude that our moderately intense exercise regimen has strong effects on hepatic glucose metabolism, but IL-6 is not needed for activation of the hepatic response needed to counteract the decrease in plasma glucose levels. Moreover, the data suggest that the reduced endurance capacity found in $1 l \sigma^{/-}$ mice [18] could not be attributed to impaired hepatic glucose production during exercise.

While the IL-6-deficiency had no apparent effect on the variables of hepatic glucose metabolism determined in the fasting state or after moderate intense exercise, fed and sedentary $1 l 6^{/-}$mice did have a mild metabolic alteration compared with wild-type mice. They had slightly higher plasma glucose levels in the fed state and also higher hepatic PEPCK protein levels. This could be due to the recently discovered role of hepatic IL-6 and STAT3 in 
suppression of gluconeogenesis. Thus it has been shown that insulin action in the hypothalamus activates IL-6 production in non-parenchymal intrahepatic cells, leading to STAT3 activation and suppression of Pepck and G6pase expression, a cascade interrupted in $I l \sigma^{/-}$mice [39, 40]. Thus the higher plasma glucose concentrations and hepatic PEPCK protein levels could reflect impaired suppression of hepatic gluconeogenesis in fed $\mathrm{IlO}^{/-}$mice. Moreover, $\mathrm{Il}^{-/}$ mice tended to have higher plasma insulin levels in the nonfasting state (difference non-significant in fed group, significant in sedentary group), which could be secondary to the slightly higher glucose concentrations. While these higher insulin levels are not able to overcome the impaired suppression of gluconeogenesis due to the lack of IL-6, they might lead to the lower NEFA concentrations seen in the non-fasted state due to better suppression of lipolysis and higher hepatic glycogen levels. Moreover, $I l \sigma^{-1}$ mice have a markedly higher insulin/glucagon ratio in the non-fasting state, which could be due not only to higher insulin levels, but also to the lacking effect of IL- 6 on pancreatic alpha cells and glucagon secretion, which presumably results in slightly lower glucagon levels, although alpha and beta cell mass are not different under chow-fed conditions [41]. The higher insulin levels in $\mathrm{Il \sigma}^{-}$mice in the fed state might also be secondary to mild insulin resistance in these animals. The glucose tolerance test did not reveal differences compared with wild-type mice, a finding well in line with earlier reports [41, 42], but the higher glucose levels found during the insulin challenge under non-fasting conditions might again be explained by the impaired suppression of gluconeogenesis. Since in mice IL-6 deficiency does not result in enhanced insulin sensitivity or prevent development of insulin resistance after feeding a high-fat diet [41-43], our data obtained with $I l \sigma^{-1}$ mice do not support the notion that IL-6 is an important mediator of insulin resistance in mice. Human studies have implicated increased circulating IL-6 levels in the development of insulin resistance [44-46], but this remains a matter of great debate [47].

In conclusion, a mild metabolic phenotype of $116^{/-}$mice became evident in non-fasting conditions and could be explained by impaired suppression of hepatic gluconeogenesis. However, this metabolic alteration had no apparent influence on glucose metabolism after an overnight fast. Thus, the data indicate that in mice IL- 6 plays a role in suppression of gluconeogenesis and is important for induction of genes involved in the regulation of glucose homeostasis during hepatic tissue repair. However, IL-6 is not necessary for glucose production during non-exhaustive exercise.

Acknowledgements This study was supported by grants from the Deutsche Forschungsgemeinschaft to C. Weigert (WE 4176) and to E. D. Schleicher (GRK 1302/1). We gratefully acknowledge the technical assistance of I. Riedlinger and E. Metzinger.
Duality of interest The authors declare that there is no duality of interest associated with this manuscript.

\section{Reference}

1. Wahren J, Ekberg K (2007) Splanchnic regulation of glucose production. Annu Rev Nutr 27:329-345

2. Camacho RC, Donahue EP, James FD, Berglund ED, Wasserman DH (2006) Energy state of the liver during short-term and exhaustive exercise in C57BL/6J mice. Am J Physiol Endocrinol Metab 290:E405-E408

3. Kjaer M (1998) Hepatic glucose production during exercise. Adv Exp Med Biol 441:117-127

4. Christ B, Nath A, Heinrich PC, Jungermann K (1994) Inhibition by recombinant human interleukin- 6 of the glucagon-dependent induction of phosphoenolpyruvate carboxykinase and of the insulin-dependent induction of glucokinase gene expression in cultured rat hepatocytes: regulation of gene transcription and messenger RNA degradation. Hepatology 20:1577-1583

5. Inoue H, Ogawa W, Ozaki M et al (2004) Role of STAT-3 in regulation of hepatic gluconeogenic genes and carbohydrate metabolism in vivo. Nat Med 10:168-174

6. Lienenluke B, Christ B (2007) Impact of interleukin-6 on the glucose metabolic capacity in rat liver. Histochem Cell Biol 128:371-377

7. Metzger S, Goldschmidt N, Barash V et al (1997) Interleukin-6 secretion in mice is associated with reduced glucose-6-phosphatase and liver glycogen levels. Am J Physiol 273:E262-E267

8. Heinrich PC, Behrmann I, Haan S, Hermanns HM, Muller-Newen G, Schaper F (2003) Principles of interleukin (IL)-6-type cytokine signalling and its regulation. Biochem J 374:1-20

9. Ramadoss P, Unger-Smith NE, Lam FS, Hollenberg AN (2009) STAT3 targets the regulatory regions of gluconeogenic genes in vivo. Mol Endocrinol 23:827-837

10. Blumberg D, Hochwald S, Brennan MF, Burt M (1995) Interleukin-6 stimulates gluconeogenesis in primary cultures of rat hepatocytes. Metabolism 44:145-146

11. Leu JI, Crissey MA, Leu JP, Ciliberto G, Taub R (2001) Interleukin-6-induced STAT3 and AP-1 amplify hepatocyte nuclear factor 1-mediated transactivation of hepatic genes, an adaptive response to liver injury. Mol Cell Biol 21:414-424

12. Ritchie DG (1990) Interleukin 6 stimulates hepatic glucose release from prelabeled glycogen pools. Am J Physiol 258:E57-E64

13. Vaartjes WJ, de Haas CG, Houweling M (1990) Acute effects of interleukin 1 alpha and 6 on intermediary metabolism in freshly isolated rat hepatocytes. Biochem Biophys Res Commun 169:623-628

14. Tsigos C, Papanicolaou DA, Kyrou I, Defensor R, Mitsiadis CS, Chrousos GP (1997) Dose-dependent effects of recombinant human interleukin-6 on glucose regulation. J Clin Endocrinol Metab 82:4167-4170

15. Steensberg A, van Hall G, Osada T, Sacchetti M, Saltin B, Klarlund PB (2000) Production of interleukin-6 in contracting human skeletal muscles can account for the exercise-induced increase in plasma interleukin-6. J Physiol 529:237-242

16. Penkowa M, Keller C, Keller P, Jauffred S, Pedersen BK (2003) Immunohistochemical detection of interleukin-6 in human skeletal muscle fibers following exercise. FASEB J 17:2166-2168

17. Febbraio MA, Hiscock N, Sacchetti M, Fischer CP, Pedersen BK (2004) Interleukin-6 is a novel factor mediating glucose homeostasis during skeletal muscle contraction. Diabetes 53:1643-1648

18. Faldt J, Wernstedt I, Fitzgerald SM, Wallenius K, Bergstrom G, Jansson JO (2004) Reduced exercise endurance in interleukin-6deficient mice. Endocrinology 145:2680-2686 
19. Weigert C, Hennige AM, Lehmann R et al (2006) Direct cross-talk of interleukin-6 and insulin signal transduction via insulin receptor substrate-1 in skeletal muscle cells. J Biol Chem 281:7060-7067

20. Chan TM, Exton JH (1976) A rapid method for the determination of glycogen content and radioactivity in small quantities of tissue or isolated hepatocytes. Anal Biochem 71:96-105

21. Hiscock N, Chan MH, Bisucci T, Darby IA, Febbraio MA (2004) Skeletal myocytes are a source of interleukin- 6 mRNA expression and protein release during contraction: evidence of fiber type specificity. FASEB J 18:992-994

22. Rosendal L, Sogaard K, Kjaer M, Sjogaard G, Langberg H, Kristiansen J (2004) Increase in interstitial interleukin-6 of human skeletal muscle with repetitive low-force exercise. J Appl Physiol 182:379-388

23. Helge JW, Stallknecht B, Pedersen BK, Galbo H, Kiens B, Richter EA (2003) The effect of graded exercise on IL-6 release and glucose uptake in human skeletal muscle. J Physiol 546:299-305

24. Carey AL, Steinberg GR, Macaulay SL et al (2006) Interleukin-6 increases insulin-stimulated glucose disposal in humans and glucose uptake and fatty acid oxidation in vitro via AMPactivated protein kinase. Diabetes 55:2688-2697

25. Glund S, Deshmukh A, Long YC et al (2007) IL-6 directly increases glucose metabolism in resting human skeletal muscle. Diabetes 56:1630-1637

26. Al Khalili L, Bouzakri K, Glund S, Lonnqvist F, Koistinen HA, Krook A (2006) Signaling specificity of interleukin-6 action on glucose and lipid metabolism in skeletal muscle. Mol Endocrinol 20:3364-3375

27. Bruce CR, Dyck DJ (2004) Cytokine regulation of skeletal muscle fatty acid metabolism: effect of interleukin- 6 and tumor necrosis factor- $\alpha$. Am J Physiol Endocrinol Metab 287:E616-E621

28. van Hall G, Steensberg A, Sacchetti M et al (2003) Interleukin-6 stimulates lipolysis and fat oxidation in humans. J Clin Endocrinol Metab 88:3005-3010

29. Ruderman NB, Keller C, Richard AM et al (2006) Interleukin-6 regulation of AMP-activated protein kinase: potential role in the systemic response to exercise and prevention of the metabolic syndrome. Diabetes 55(Suppl 2):S48-S54

30. Banzet S, Koulmann N, Simler N et al (2009) Control of gluconeogenic genes during intense/prolonged exercise: hormone-independent effect of muscle-derived IL-6 on hepatic tissue and PEPCK mRNA. J Appl Physiol 107:1830-1839

31. Weigert C, Duefer M, Simon P et al (2007) Upregulation of IL-6 mRNA by IL- 6 in skeletal muscle cells: role of IL- 6 mRNA stabilization and $\mathrm{Ca}^{2+}$-dependent mechanisms. Am J Physiol Cell Physiol 293:C1139-C1147

32. Huang CC, Lin WT, Hsu FL, Tsai PW, Hou CC (2009) Metabolomics investigation of exercise-modulated changes in metabolism in rat liver after exhaustive and endurance exercises. Eur J Appl Physiol 108:557-566

33. Aldeguer X, Debonera F, Shaked A et al (2002) Interleukin-6 from intrahepatic cells of bone marrow origin is required for normal murine liver regeneration. Hepatology 35:40-48

34. Cressman DE, Greenbaum LE, DeAngelis RA et al (1996) Liver failure and defective hepatocyte regeneration in interleukin-6deficient mice. Science 274:1379-1383

35. Li W, Liang X, Leu J, Kovalovich K, Ciliberto G, Taub R (2001) Global changes in interleukin-6-dependent gene expression patterns in mouse livers after partial hepatectomy. Hepatology 33:1377-1386

36. Kubota N, Kubota T, Itoh S et al (2008) Dynamic functional relay between insulin receptor substrate 1 and 2 in hepatic insulin signaling during fasting and feeding. Cell Metab 8:49-64

37. Anthony TG, Anthony JC, Lewitt MS, Donovan SM, Layman DK (2001) Time course changes in IGFBP-1 after treadmill exercise and postexercise food intake in rats. Am J Physiol Endocrinol Metab 280:E650-E656

38. Hoene M, Lehmann R, Hennige AM et al (2009) Acute regulation of metabolic genes and insulin receptor substrates in the liver of mice by one single bout of treadmill exercise. J Physiol 587:241-252

39. Konner AC, Janoschek R, Plum L et al (2007) Insulin action in AgRP-expressing neurons is required for suppression of hepatic glucose production. Cell Metab 5:438-449

40. Inoue H, Ogawa W, Asakawa A et al (2006) Role of hepatic STAT3 in brain-insulin action on hepatic glucose production. Cell Metab 3:267-275

41. Ellingsgaard H, Ehses JA, Hammar EB et al (2008) Interleukin-6 regulates pancreatic alpha-cell mass expansion. Proc Natl Acad Sci U S A 105:13163-13168

42. Di Gregorio GB, Hensley L, Lu T, Ranganathan G, Kern PA (2004) Lipid and carbohydrate metabolism in mice with a targeted mutation in the IL- 6 gene: absence of development of age-related obesity. Am J Physiol Endocrinol Metab 287:E182-E187

43. Wallenius V, Wallenius K, Ahren B et al (2002) Interleukin-6deficient mice develop mature-onset obesity. Nat Med 8:75-79

44. Pradhan AD, Manson JE, Rifai N, Buring JE, Ridker PM (2001) C-reactive protein, interleukin 6 , and risk of developing type 2 diabetes mellitus. JAMA 286:327-334

45. Fernandez-Real JM, Vayreda M, Richart C et al (2001) Circulating interleukin 6 levels, blood pressure, and insulin sensitivity in apparently healthy men and women. J Clin Endocrinol Metab 86:1154-1159

46. Cardellini M, Perego L, D'Adamo $M$ et al (2005) C-174G polymorphism in the promoter of the interleukin-6 gene is associated with insulin resistance. Diabetes Care 28:2007-2012

47. Allen TL, Febbraio MA (2010) IL-6 as a mediator of insulin resistance: fat or fiction? Diabetologia 53:399-402 